\title{
MULHERES NA MINERAÇÃO: CARREIRA, EQUILÍBRIO TRABALHO-FAMÍLIA E DISCRIMINAÇÃO
}

\author{
WOMEN IN THE MINING: \\ CAREER, BALANCE-FAMILY WORK AND DISCRIMINATION
}

\section{SABRINA SILVA VALADARES}

Coordenadora de Atração de Talentos - Anglo American Brasil Ltda Mestre em Administração - Pontifícia Universidade Católica de Minas Gerais Orcid: https://orcid.org/0000-0001-5274-1562 / E-mail: sabrinavaladares@yahoo.com.br Av. Itaú, 525, Bairro Dom Cabral, Belo Horizonte/MG, CEP: 30535012

\section{ANTÔNIO MOREIRA DE CARVALHO NETO}

Docente do Programa de Pós-graduação em Administração - PUC Minas Doutor em Administração - Universidade Federal de Minas Gerais (UFMG) Orcid: https://orcid.org/0000-0001-5439-2845 / E-mail: carvalhoneto@pucminas.br

\section{DANIELA MARTINS DINIZ}

Docente do Programa de Pós-Graduação em Propriedade Intelectual e Transferência de Tecnologia para a Inovação - Universidade Federal de São João Del Rei (UFSJ)

Doutora em Administração - Universidade Federal de Minas Gerais (UFMG) Orcid: https://orcid.org/0000-0003-1110-756X / E-mail: danidiniz09@yahoo.com.br

Submissão: 29/04/2021. Revisões: 25/05/2021; 09/11/2021. Aceite: 20/12/2021. Publicação: 01/02/2022. DOI: http://dx.doi.org/10.22277/rgo.v15i1.6314

\section{RESUMO}

Objetivo: Este artigo analisou a percepção de profissionais, mulheres e homens, acerca da condição da mulher no ambiente de trabalho em uma empresa multinacional do setor de mineração.

Método / abordagem: Uma pesquisa de campo survey foi aplicada em uma multinacional do setor de mineração contemplando uma amostra de 262 empregados.

Principais resultados: Os resultados apontam que os homens apresentaram maior tendência de concordância em relação às questões sobre a carreira da mulher, ou seja, claramente os profissionais do sexo masculino percebem menos as barreiras à carreira das mulheres do que elas próprias. Quando ao indicador Preconceito e Discriminação, observou-se diferença significativa de percepção entre o sexo feminino e o masculino, evidenciando uma percepção mais aguçada das mulheres quanto à ocorrência de situações de preconceito e discriminação na organização. No indicador Trabalho e Família, diferentemente do esperado, os dados apontam que não houve diferença significativa de percepção entre o sexo feminino e masculino.

Contribuições metodológicas / sociais / gerenciais: A pesquisa confirma barreiras vivenciadas pelas mulheres no quesito ascensão e desenvolvimento de carreira e corrobora a existência de situações de preconceito em contextos marcados pela hegemonia do masculino.

Este é um artigo publicado em acesso aberto (Open Access) sob a licença Creative Commons Attribution, que permite uso, distribuição e reprodução em qualquer meio, sem restrições desde que o trabalho original seja corretamente citado. 
Originalidade / relevância: A mulher na mineração foi abordada em apenas um estudo nacional e, ao trazer à tona esse debate, o artigo reforça a importância de se pensar na elaboração de políticas e práticas focadas nas necessidades da mulher para que elas possam obter iguais condições de trabalho, salário e ascensão nas organizações.

Palavras-chave: Ambiente de trabalho. Percepção de homens e de mulheres. Mineração.

\section{ABSTRACT}

Purpose: This article analyzed the perception of professionals, women, and men, about the condition of women in the workplace in a multinational company in the mining sector.

Method / approach: A survey field research was applied in a multinational in the mining sector, covering a sample of 262 employees.

Main findings: The results show that men showed a greater tendency to agree in relation to questions about women's careers, that is, male professionals clearly perceive less barriers to women's careers than they do. As for the Prejudice and Discrimination indicator, there was a significant difference in perception between females and males, evidencing a sharper perception of women regarding the occurrence of situations of prejudice and discrimination in the organization. In the Work and Family indicator, differently from what was expected, the data show that there was no significant difference in perception between females and males.

Methodological / social / managerial contributions: The research confirms barriers experienced by women in terms of career advancement and development and corroborates the existence of situations of prejudice in contexts marked by male hegemony.

Originality / relevance: Women in mining was addressed in only one national study and, by bringing this debate to the fore, the article reinforces the importance of thinking about the development of policies and practices focused on women's needs so that they can obtain equal working conditions, salary and advancement in organizations.

Keywords: Working environment. Perception of men and women. Mining.

\section{INTRODUÇÃO}

Enfrentando ainda barreiras consideráveis, a mulher vem conseguindo conquistar espaços e posições jamais ocupados anteriormente no mercado de trabalho (Rocha-Coutinho; \& Coutinho, 2011; Silva et al., 2016; Antunes et al., 2018; Mota-Santos et al., 2019). Pesquisa sobre a Relação Anual de Informações Sociais (RAIS) do Ministério da Economia, por exemplo, apontou uma expansão significativa da ocupação das mulheres no mercado de trabalho brasileiro, saindo de uma participação de 13,6\% em 1950 para 44\% em 2019 (Brasil, 2019). As estatísticas sobre gênero do IBGE (2021) também corroboram esse cenário, indicando que o percentual de mulheres no mercado ampliou pelo quinto ano consecutivo, porém elas continuam recebendo salários inferiores e ocupando poucos cargos gerenciais.

As mulheres continuam de certa forma ainda confinadas em guetos profissionais, em atividades mais associadas ao cuidado, à saúde, às funções de apoio, tradicionalmente relacionadas a uma concepção preconceituosa de que cabe à mulher principalmente cuidar, não coordenar. Diferentemente dos homens, direcionados a atividades de execução, direção e planejamento, que são muito mais valorizadas nas organizações (Silva et al., 2016; Antunes et al., 2018). Inclusive nas atividades mais demandadas pelas profundas transformações causadas no mercado de trabalho pela atual revolução 4.0 (Susskind \& Susskind, 2017). 
O mundo corporativo ainda sob a dominação masculina, onde a discriminação por sexo no ambiente organizacional persiste nos salários diferenciados, na tripla jornada de trabalho, na menor inserção ocupacional, nas menores chances de promoção na carreira e até mesmo nas condições de trabalho menos favoráveis (Gibb et al., 2013; Tanure et al., 2014; Silva et al., 2016; Mota-Santos et al., 2017; Oliveira et al., 2018; Mota-Santos et al., 2019).

Essas formas de discriminação são ainda mais visíveis na mineração, lócus deste estudo. $O$ setor de extração de minérios resiste às mudanças e é socialmente reconhecido como mais "adequado" aos homens (Quirino, 2011; Funtealba \& Gutierrez, 2018). Ou seja, marcado por uma percepção histórico e social de trabalho pesado, que exige força física e resistência, as atividades no setor minerário vão ao encontro do estereótipo que se tem da masculinidade (Castilhos \& Castro, 2006; Pimpa, 2019).

Historicamente a presença das mulheres nas minas significava má sorte, crença que poderia explicar a ocorrência de acidentes, mortes e até mesmo o esgotamento do minério. Todos esses preconceitos, aliados a uma cultura patriarcal, fez emergir uma concepção de que o trabalho nas minas deveria ser feito por homens em virtude de suas duras condições, e que somente eles teriam resistência física para exercê-lo (Castilhos \& Castro, 2006).

Na literatura, apesar de muitas contribuições sobre a mulher no mercado de trabalho, especialmente as que têm alta qualificação (Vieira \& Amaral, 2013; Henderson et al., 2016; Mota-Santos et al., 2017), ainda há no Brasil poucos estudos em setores econômicos em que prevalece a presença masculina, e ainda menos na mineração, segmento aqui estudado.

Dado o exposto, este artigo analisou a percepção de profissionais, mulheres e homens, acerca da condição da mulher no ambiente de trabalho em uma grande empresa multinacional do setor de mineração. Para tanto, foi mensurado o nível de concordância dos funcionários da organização em relação a questões sobre a carreira da mulher, situações de preconceito e discriminação e conciliação do trabalho e família pelas profissionais do sexo feminino. Além disso, foi analisada a relação entre as questões de pesquisa e as variáveis de caracterização dos respondentes, quais sejam: estado civil, idade, tempo de trabalho, escolaridade, cargo e o local de trabalho.

Numa consulta realizada, em abril de 2021, no Scientific Periodicals Electronic Library (SPELL) da Associação Nacional de Pós-Graduação e Pesquisa em Administração (ANPAD), com as palavras-chave "mulher" e "mineração" no título e resumo dos trabalhos, foram identificadas somente 2 publicações sobre o tema. Além disso, somente uma trata das condições de trabalho da mulher neste segmento (Macedo et al., 2012), o que é um indicador da relevância deste estudo.

\section{A MULHER NO MERCADO DE TRABALHO}

O movimento mais significativo de entrada da mulher no mercado de trabalho no Ocidente ocorreu porque o homem, até então provedor principal, não conseguia cumprir plenamente seu papel, devido à convocação militar para participar da Primeira Guerra Mundial nos países envolvidos no conflito (Teixeira, 2009). Consequentemente, a inserção da mulher no mercado foi marcada pela ocupação de espaços mais precarizados (Abramo, 2007).

Além disso, a mulher não abandou as tarefas domésticas de cuidado do lar e dos filhos, passando a acumular funções dentro e fora de casa. Tal situação reforçou, de alguma forma, a divisão sexual do trabalho, construto social presente nas relações sociais entre homens e mulheres com a finalidade de garantir interesses e poder da dominação masculina (Quirino, 
2011; Guiraldelli, 2012). Portanto, foi se organizando a família operária patriarcal, na qual o marido era o provedor principal e a esposa dona de casa e provedora complementar, estabelecendo uma divisão sexual do trabalho desigual que deixa resquícios até os dias atuais.

Apesar da inserção precarizada da mulher no mercado de trabalho, no plano internacional, a entrada no espaço público trouxe experiências de liberdade e responsabilidade para as mulheres. Além disso, possibilitou o aumento de sua autoestima e competência, pois a mulher passou a manusear instrumentos e técnicas antes inacessíveis e desconhecidas (Cappelle et al., 2013).

Ainda no plano internacional, a crescente industrialização, no século XIX, também foi considerada um dos principais impulsionadores da inserção das mulheres no mercado de trabalho, trazendo novas possibilidades de atuação profissional para as mulheres (Costa, 2020). Atingindo inclusive o Brasil, este desenvolvimento industrial do século XIX altera a situação da mulher, transformando-a em força de trabalho e incorporando-a à classe trabalhadora (Quirino, 2011). Todavia, essa inclusão ocorre pela ocupação de atividades de baixa capacidade técnica (Rocha-Coutinho \& Coutinho, 2011; Daniel, 2011; Nascimento, 2014; Valadares, 2016).

Estudos nacionais indicam que a divisão do trabalho entre homens e mulheres estabeleceu-se com a justificativa de que as mulheres não detinham conhecimento e experiência para supervisionar as atividades, evidenciando mais uma vez o caráter de superioridade dos homens sobre as mulheres (Teixeira, 2009; Quirino, 2011). Portanto, apesar de o trabalho fora de casa ter representado uma libertação para a mulher, por outro lado, Ihe impôs uma dupla jornada de trabalho e certa alienação, uma vez que ela era oprimida e explorada em casa e nas fábricas (Quirino, 2011). Além disso, a mulher não era remunerada nos mesmos patamares que o homem (Costa, 2020).

$\mathrm{O}$ acesso ao trabalho formal e assalariado no Brasil não se traduziu necessariamente em maior bem-estar e independência para as mulheres. Elas continuavam a ocupar um lugar inferior na sociedade, inclusive sendo expostas a situações de desqualificação, discriminação, assédio sexual, distinções salariais e intimidações físicas (Mota-Santos, 2012).

Diante desse cenário, assim como de pressões sociais e familiares, inicia-se um movimento de retirada da mulher das camadas mais abastadas do mercado de trabalho brasileiro. Ela passa a ser substituída por profissionais do sexo masculino com a justificativa de que a mulher continuava incapaz de manejar máquinas e tecnologias cada vez mais presentes nas organizações (Daniel, 2011). Ademais, o trabalho feminino na fábrica passa a ser degradante para a imagem da mulher, como se ela estivesse abandonando as atividades do lar (Valadares, 2016).

No Brasil, o início do século XX foi marcado pela redução significativa das mulheres nas fábricas (Mota-Santos, 2012). Por outro lado, foi caracterizado pelo ingresso das brasileiras no mercado de trabalho preenchendo funções de apoio (coo, secretária), de professora e médica (Cappelle et al., 2013). A ocupação de outras posições pela mulher e em atividades que exigiam mais conhecimento acadêmico foi o reflexo do surgimento de escolas do magistério no final do século XIX que ofertavam cursos considerados adequadas à natureza da mulher.

Estudos nacionais indicam que o período pós Segunda Guerra Mundial foi uma época fértil para as mulheres ocuparem alguns espaços dos homens no mercado de trabalho e elas se mostraram dispostas a não abrir mão dessa posição como anteriormente ocorrera (Daniel, 2011; Mota-Santos, 2012). Nesta fase observou-se maior aceitação da força de trabalho feminina decorrente de mudanças na oferta da força de trabalho, da queda dos salários 
médios familiares e do aumento da exigência quanto à escolaridade e formação, entre outros (Cappelle et al., 2013).

Apesar dessa inserção gradativa da mulher no mercado de trabalho brasileiro, até o início dos anos de 1960, ter uma carreira era algo difícil para parte significativa das mulheres, visto que o acesso à educação era para um grupo seleto e restrito (Mota-Santos et al., 2017). Na década de 1970, foi no ambiente do regime militar e de forma muito limitada pelas condições que o Brasil vivia na época que aconteceram as primeiras movimentações feministas (Pinto, 2010).

Estudos nacionais indicam que as últimas décadas do século $X X$ foram marcadas por transformações demográficas, culturais e sociais que impactaram diretamente o aumento do trabalho feminino, como a queda da taxa de fecundidade, maior expectativa de vida da mulher em comparação ao homem e uma tendência de crescimento de estruturas familiares chefiadas por mulheres (Quirino, 2011; Bruschini \& Lombardi, 2016). Passava-se de um cenário no qual as mulheres que trabalhavam eram geralmente jovens, solteiras e sem filhos, para outro em que as mulheres eram mais velhas, casadas e mães (Quirino, 2011; Bruschini \& Lombardi, 2016).

O início do século XXI foi um período de maior qualificação das mulheres, marcando o início da inserção delas em atividades até então exercidas majoritariamente pelos homens. Não obstante, já era possível perceber diferenças no tratamento do homem e da mulher no trabalho, sobretudo em relação a questões salariais e da função que cada um ocupava.

Com a consolidação da participação da mulher no mercado de trabalho brasileiro, ela se vê obrigada a lidar com o paradoxo entre o trabalho externo e o doméstico, desafio que persiste na maioria das famílias brasileiras (Bruschini, 1994). A dupla jornada de trabalho e a dificuldade de compartilhar as atividades do lar com o homem, que muitas vezes se encontra indisponível, geram uma sobrecarga para a mulher que ainda carrega o peso da tradição de ser mãe e esposa (Tanure et al., 2014). Portanto, a "mulher saiu de casa", porém o "homem não entrou", caracterizando a realidade de muitos lares brasileiros onde há essa sobrecarga da mulher em decorrência da sua dupla jornada de trabalho (Valadares, 2016).

Portanto, conciliar essas diversas demandas com um bom desempenho no trabalho e uma busca constante de reafirmação do seu espaço nas organizações no Brasil se torna algo não apenas exaustivo, mas impactante para a saúde mental da mulher (Bruschini, 1994).

A despeito das mudanças ocorridas nas últimas décadas, o fato é que ainda se vive uma relação de diferenças entre o homem e a mulher no mercado de trabalho brasileiro. A participação da mulher continua crescendo no mercado, mas ela ainda não se iguala ao homem em termos salariais e de ascensão na carreira (Mota-Santos et al., 2017).

Essa realidade evidencia que, embora o trabalho feminino tenha sido aceito, a segregação de gênero ainda presente em diversas profissões contribui para a perpetuação de alguns estereótipos, justificando as diferenças salariais e dificultando a ascensão da mulher nas organizações (Santos \& Amâncio, 2014). Ainda são atribuídos à mulher traços de fragilidade, emotividade e submissão; e aos homens, traços de ousadia, poder de decisão e racionalidade, tornando os profissionais do sexo masculino mais aptos a ocupar posições hierárquicas superiores nas organizações (Carvalho Neto, Tanure \& Andrade, 2010).

Além disso, a inserção da mulher no mercado de trabalho brasileiro segue acompanhada de segregações e descriminações que as colocam em condições menos favoráveis nas organizações (Galeazzi et al., 2011). O preconceito é um dos responsáveis pela 
dificuldade de ascensão das mulheres e se manifesta em aspectos como uma maior exposição ao risco do desemprego, a segregação ocupacional e a discriminação nos rendimentos, desafios também vivenciados pelas mulheres no contexto da mineração, conforme corroboram estudos na área (Castilhos \& Castro, 2006; Norberg \& Falthlom, 2018; Buss et. al., 2019; Pimpa, 2019).

As mulheres não são reconhecidas como parte integrante do ambiente minerador e, por esse motivo, são alvos de discriminação, resistência e assédio. Essa norma estabelecida e que governa a atuação da mulher na mineração, a exclui de determinados postos de trabalho. Seu trabalho se concentra em atividades que são classificadas como complementares na mineração (Norberg \& Falthlom, 2018).

O papel da mulher nas mineradoras foi historicamente sendo construído como espelho de suas responsabilidades domésticas, de transportar água, fornecer comida e apoiar os homens. Isto reflete no contexto atual, considerando-se a designação das mulheres para cargos em atividades administrativas e de suporte, que, por si só, teve e tem menor valor que aquelas propriamente de mineração (Pimpa, 2019)

Ademais, como as mineradoras adotam um modelo de produção ininterrupta, elas atuam com longas e intensas jornadas de trabalho, o que, por si só, dificulta a conciliação entre vida profissional e responsabilidades familiares (Buss et. al., 2019).

\section{ASPECTOS METODOLÓGICOS}

Quanto ao método, foi desenvolvida pesquisa de natureza quantitativa a partir da aplicação de uma survey em uma multinacional do setor de mineração. A organização estudada possui mais de 100 anos no setor, ou seja, larga experiência no mercado de mineração, um dos principais critérios adotados para a seleção do objeto investigado.

As unidades empíricas selecionadas para o estudo foram seis unidades localizadas em três estados brasileiros (Minas Gerais, Rio de Janeiro e Goiás), envolvendo respondentes vinculados à diferentes áreas da empresa, sendo: i) Mina de lavra e beneficiamento; ii) Estação de controle de Bombas; iii) Filtragem e Embarque de minério; iv) Mina de extração e beneficiamento; v) Usina/ Beneficiamento; vi) Suporte geral e administrativo.

A elaboração do instrumento de pesquisa foi feita em cinco etapas: a) revisão teórica sobre o tema para levantamento das categorias de análise da pesquisa (carreira, preconceito e discriminação, trabalho/família); b) elaboração da primeira versão do questionário; c) realização de pré-teste do instrumento com duas profissionais da organização; d) revisão do questionário por um estatístico profissional.

A versão final do questionário contemplou dezenove questões relacionadas à três indicadores, conforme Tabela 1. A escala adotada foi a Likert de cinco pontos, sendo um (01) discordo totalmente e cinco (5) concordo totalmente (Gil, 2002).

O link com o questionário foi publicado nos meios de comunicação da mineradora, especificamente, no jornal semanal, na intranet e nos murais físicos da empresa, bem como foi enviado no WhatsApp e no aplicativo de comunicação da organização. Portanto, não houve uma seleção prévia dos participantes, permitindo-se que todos os funcionários da empresa pudessem participar da pesquisa. Entretanto, dos 3.690 empregados registrados formalmente, somente 262 responderam ao questionário. Ressalta-se, ainda, que o link da pesquisa ficou disponível no período de 02 de setembro de 2020 a 17 de setembro de 2020 . 
Tabela 1

Variáveis da pesquisa

\begin{tabular}{|c|c|c|}
\hline Indicador & Item & Legenda \\
\hline \multirow{11}{*}{ 1) Carreira } & Q1 & Acredito que a mulher é capaz de exercer qualquer função/cargo na empresa. \\
\hline & Q2 & Existem iniciativas de desenvolvimento de carreira para mulheres na empresa. \\
\hline & Q3 & $\begin{array}{l}\text { A empresa utiliza critérios justos e claros para as promoções e oportunidades de carreira, } \\
\text { sem influências quanto ao sexo dos empregados. }\end{array}$ \\
\hline & Q4 & Para determinadas posições existem restrições da empresa quanto a atuação da mulher. \\
\hline & Q5 & $\begin{array}{l}\text { Não existem diferenças salariais entre homens e mulheres que estejam no mesmo cargo } \\
\text { e pelo mesmo período na empresa. }\end{array}$ \\
\hline & Q6 & $\begin{array}{l}\text { Os processos de recrutamento e seleção são conduzidos de forma igualitária, } \\
\text { independente do sexo. }\end{array}$ \\
\hline & Q7 & Tenho expectativa de alcançar novos cargos e ter crescimento na empresa. \\
\hline & Q8 & Nunca presenciei situações de discriminação e preconceito na empresa contra a mulher \\
\hline & Q9 & $\begin{array}{l}\text { Já presenciei situações no ambiente de trabalho, onde a ideia de uma mulher foi utilizada } \\
\text { sem dar crédito a ela. }\end{array}$ \\
\hline & Q10 & $\begin{array}{l}\text { Já presenciei situações, em reuniões e no ambiente de trabalho em geral, no qual uma } \\
\text { mulher é interrompida por um homem ao falar ou realizar uma apresentação. }\end{array}$ \\
\hline & Q11 & Já presenciei situações de uma mulher ser diminuída psicologicamente no trabalho \\
\hline \multirow{6}{*}{$\begin{array}{l}\text { 2) } \\
\text { Preconceito e } \\
\text { discriminação }\end{array}$} & Q12 & As mulheres são alvos de brincadeiras e piadas no ambiente de trabalho. \\
\hline & Q13 & $\begin{array}{l}\text { Já soube ou presenciei, no ambiente de trabalho, situações de assédio sexual (conduta } \\
\text { ou atenção indesejada de natureza sexual) contra mulher. }\end{array}$ \\
\hline & Q14 & $\begin{array}{l}\text { Já soube ou presenciei, no ambiente de trabalho, de situações de assédio moral (conduta } \\
\text { indesejada que viola a dignidade) contra mulher. }\end{array}$ \\
\hline & Q15 & $\begin{array}{l}\text { Já soube ou presenciei, no ambiente de trabalho, de situações de bullying } \\
\text { (comportamento repetitivo e indesejado que é ofensivo) contra a mulher. }\end{array}$ \\
\hline & Q16 & $\begin{array}{l}\text { Já presenciei situações no ambiente de trabalho no qual o homem tomou a palavra da } \\
\text { mulher para explicar algo que ela acabou de dizer. }\end{array}$ \\
\hline & Q17 & $\begin{array}{l}\text { Me sinto confortável em recusar uma demanda de trabalho por ela estar incompatível } \\
\text { com meu horário de trabalho, ou devido outros compromissos pessoais/ familiares. }\end{array}$ \\
\hline \multirow[t]{2}{*}{$\begin{array}{l}\text { 3) Trabalho e } \\
\text { Família }\end{array}$} & Q18 & $\begin{array}{l}\text { Já avaliei a possibilidade de sair da empresa devido à dificuldade de conciliar o trabalho } \\
\text { com questões pessoais/ familiares. }\end{array}$ \\
\hline & Q19 & $\begin{array}{l}\text { Conciliar minha atuação profissional com questões familiares é uma das minhas } \\
\text { principais dificuldades atualmente. }\end{array}$ \\
\hline
\end{tabular}

Para o tratamento dos dados empíricos foi utilizado o software $\mathrm{R}$ - versão 4.0.2. $\mathrm{Na}$ análise descritiva das variáveis numéricas foram utilizadas medidas de posição, tendência central e dispersão e para descrever as variáveis de caracterização foram utilizadas as frequências absolutas e relativas. Para descrever e comparar os itens dos indicadores investigados, além das medidas de posição, tendência central e dispersão, utilizou-se o intervalo percentílico bootstrap de 95\% de confiança (Efron \& Tibshiranii, 1993).

Para comparar os indicadores investigados com as variáveis de caracterização, utilizouse o teste de Mann-Whitney para variáveis com 2 níveis e o de Kruskal-Wallis para variáveis com mais de 2 níveis. Para verificar a correlação entre as variáveis ordinais numéricas e os indicadores investigados, foi utilizada a correlação de Spearman (Hollander \& Wolfe, 1999).

A Tabela 2 apresenta as variáveis de caracterização da amostra. Ressalta-se que a escolha pela amostra mista permitiu a comparação entre as respostas dadas pelas mulheres e as dos homens em alguns indicadores avaliados no estudo, como pode ser visto na seção 4 . 
Mulheres na mineração: carreira, equilíbrio trabalho-família e discriminação

Tabela 2

Análise descritiva das variáveis de caracterização

\begin{tabular}{|c|c|c|c|}
\hline & Variável & $\mathbf{N}$ & $\%$ \\
\hline \multirow{3}{*}{ Sexo } & Feminino & 147 & $56,1 \%$ \\
\hline & Masculino & 86 & $32,8 \%$ \\
\hline & Prefiro não responder & 29 & $11,1 \%$ \\
\hline \multirow{5}{*}{ Estado Civil } & Casado(a) & 130 & $49,6 \%$ \\
\hline & Solteiro(a) & 90 & $34,4 \%$ \\
\hline & União Estável & 29 & $11,1 \%$ \\
\hline & Viúvo(a) & 2 & $0,8 \%$ \\
\hline & Prefiro não responder & 11 & $4,2 \%$ \\
\hline \multirow{5}{*}{ Idade } & Entre 18 e 28 anos & 57 & $21,8 \%$ \\
\hline & Entre 29 e 39 anos & 136 & $51,9 \%$ \\
\hline & Entre 40 e 50 anos & 53 & $20,2 \%$ \\
\hline & Acima de 51 anos & 13 & $5,0 \%$ \\
\hline & Prefiro não responder & 3 & $1,1 \%$ \\
\hline \multirow{6}{*}{ Tempo de trabalho } & Entre 0 e 3 anos & 107 & $40,8 \%$ \\
\hline & Entre 4 e 7 anos & 98 & $37,4 \%$ \\
\hline & Entre 8 e 11 anos & 38 & $14,5 \%$ \\
\hline & Entre 12 e 15 anos & 13 & $5,0 \%$ \\
\hline & Acima de 15 anos & 5 & $1,9 \%$ \\
\hline & Prefiro não responder & 1 & $0,4 \%$ \\
\hline \multirow{8}{*}{ Escolaridade } & Ensino Fundamental Completo & 9 & $3,4 \%$ \\
\hline & Ensino Médio/Técnico Incompleto & 13 & $5,0 \%$ \\
\hline & Ensino Médio/Técnico Completo & 32 & $12,2 \%$ \\
\hline & Ensino Superior Incompleto/Em andamento & 16 & $6,1 \%$ \\
\hline & Ensino Superior Completo & 56 & $21,4 \%$ \\
\hline & Pós-graduação Incompleto/Em andamento & 30 & $11,5 \%$ \\
\hline & Pós-graduação Completo & 104 & $39,7 \%$ \\
\hline & Prefiro não responder & 2 & $0,8 \%$ \\
\hline \multirow{6}{*}{ Número de filhos } & Não tenho filhos & 121 & $46,2 \%$ \\
\hline & 01 filho(a) & 69 & $26,3 \%$ \\
\hline & 02 filhos & 59 & $22,5 \%$ \\
\hline & 03 filhos & 10 & $3,8 \%$ \\
\hline & Acima de 03 filhos & 3 & $1,1 \%$ \\
\hline & Prefiro não responder & 0 & $0,0 \%$ \\
\hline \multirow{7}{*}{ Cargo } & Analista/Supervisor & 112 & $42,7 \%$ \\
\hline & Assistente/Técnico & 57 & $21,8 \%$ \\
\hline & Coordenador/Especialista & 34 & $13,0 \%$ \\
\hline & Diretor & 1 & $0,4 \%$ \\
\hline & Gerente & 11 & $4,2 \%$ \\
\hline & Operador/Auxiliar & 44 & $16,8 \%$ \\
\hline & Prefiro não responder & 3 & $1,1 \%$ \\
\hline
\end{tabular}

\section{APRESENTAÇÃO E DISCUSSÃO DOS RESULTADOS}

\subsection{ANÁLISE DESCRITIVA NUMÉRICA}

O fato de o questionário ter sido respondido por 147 mulheres (63,09\% da amostra) e 86 homens (Tabela 1), numa empresa com a maioria da força de trabalho composta por homens, por si só já corrobora a literatura que discute a discriminação (Bruschini, 1994; Carvalho Neto et al., 2010; Mota-Santos et al., 2019). Afinal, num mundo onde a dominação masculina é tão presente, e em especial em um setor onde a dominação é ainda mais pronunciada como a mineração, os homens sequer se deram ao trabalho de responder uma pesquisa sobre discriminação contra a mulher, mesmo a pesquisa sendo amplamente divulgada pela direção da empresa, que tem um programa institucional de gestão da diversidade desde 2019. A Tabela 3 contempla uma análise do nível de concordância e 
discordância dos respondentes acerca das questões sobre carreira, preconceito e trabalho/família.

Tabela 3

Análise descritiva dos indicadores de acordo com cada questão

\begin{tabular}{cccccc}
\hline Indicador & Item & N & Média & D.P. & I.C. (95\%) \\
\hline Carreira & Q1 & 262 & 4,61 & 0,86 & {$[4,50 ; 4,71]$} \\
& Q2 & 262 & 3,19 & 1,29 & {$[3,04 ; 3,35]$} \\
Q3 & 262 & 3,66 & 1,34 & {$[3,50 ; 3,82]$} \\
Preconceito e & Q4 & 262 & 2,77 & 1,29 & {$[2,63 ; 2,92]$} \\
discriminação & Q5 & 262 & 3,1 & 1,33 & {$[2,94 ; 3,28]$} \\
& Q6 & 262 & 3,71 & 1,25 & {$[3,54 ; 3,85]$} \\
& Q7 & 262 & 4,39 & 1,07 & {$[4,26 ; 4,51]$} \\
& Q8 & 262 & 3,51 & 1,48 & {$[3,33 ; 3,69]$} \\
& Q10 & 262 & 2,79 & 1,47 & {$[2,61 ; 2,97]$} \\
& Q11 & 262 & 2,74 & 1,59 & {$[2,57 ; 2,93]$} \\
& Q12 & 262 & 2,58 & 1,54 & {$[2,40 ; 2,78]$} \\
Trabalho e família & Q13 & 262 & 2,84 & 1,55 & {$[2,65 ; 3,03]$} \\
& Q14 & 262 & 2,85 & 1,6 & {$[2,65 ; 3,04]$} \\
& Q15 & 262 & 2,94 & 1,58 & {$[2,74 ; 3,11]$} \\
& Q16 & 262 & 2,69 & 1,53 & {$[2,50 ; 2,87]$} \\
& Q17 & 262 & 2,74 & 1,53 & {$[2,55 ; 2,92]$} \\
& Q18 & 262 & 2,91 & 1,39 & {$[2,75 ; 3,08]$} \\
& Q19 & 262 & 2,27 & 1,48 & {$[2,10 ; 2,44]$} \\
\hline
\end{tabular}

No indicador Carreira, a questão 1 (percepção de que a mulher é capaz de exercer qualquer função), a questão 2 (percepção de que existem iniciativas específicas de desenvolvimento de carreira para mulheres), a questão 3 (percepção quanto à existência de critérios justos e claros para promoção e progressão de carreira, sem influência do fator sexo), a questão 6 (percepção de que os processos seletivos são conduzidos de forma igualitária e justa) e a questão 7 (expectativa de alcançar novos cargos) obtiveram médias superiores a 3 . Esses achados indicam que os respondentes concordaram com as questões apresentadas em função da média e do intervalo de confiança que comprovam essa tendência.

Neste momento, considera-se as respostas de mulheres e homens sem diferenciação por sexo. Portanto, quando se considera as respostas de homens e mulheres juntas, sem separar por sexo, não se observa na percepção deles a discriminação apontada pela literatura (Antunes et al., 2018; Bruschini, 1994; Carvalho Neto et al., 2010; Mota-Santos et al., 2019; Rocha-Coutinho \& Coutinho, 2011; Silva et al., 2016). Isto ocorre, porque, mesmo em menor número de respondentes, os homens, ao não considerar que há discriminação, provocam no total de questões respondidas um viés de não percepção.

No entanto, ainda assim a média para a questão 4 (percepção de que existem restrições por parte da empresa quanto à atuação da mulher), foi menor que 3 , evidenciando uma tendência de discordância. Ou seja, mesmo não considerando a diferenciação das respostas por sexo, o total, incluindo os homens, tendeu a concordar que existem dificuldades para a atuação da mulher, o que reforça a literatura que enfatiza as barreiras e a discriminação enfrentada pelas mulheres (Carvalho Neto et al., 2010; Mota-Santos et al., 2019).

A média da questão 5 (não existem diferenças salariais entre mulheres e homens no mesmo cargo e tempo de empresa) foi de 3.10 , indicando um posicionamento neutro dos respondentes. Quando se considera as respostas sem diferenciação por sexo, a percepção 
geral é de que praticamente não há diferenças salariais. Em geral, de fato, numa grande empresa multinacional como a mineradora pesquisada, dificilmente se encontrará esta situação. A dificuldade pode estar mais nas barreiras que as mulheres enfrentam para ocupar cargos mais bem remunerados do que propriamente em diferenças dentro do mesmo cargo.

Novamente, considerando o conjunto de mulheres e homens, estes parecem não concordar com a ocorrência de situações de assédio moral, sexual e bullying contra a mulher na organização investigada, diferentemente do que indicam os estudos sobre a mulher na mineração (Castilhos \& Castro, 2006; Carrilho, 2016) e a literatura em geral (Quirino, 2011; Guiraldelli, 2012). Tal achado contrasta o resultado de pesquisa evidenciado na Tabela 5 no tópico subsequente, onde as respostas foram separadas por sexo e as mulheres manifestaram percepção oposta a esta, de existência de situações de preconceito no ambiente de trabalho.

No indicador Trabalho e Família, dois itens (exceto o 17) apresentaram o intervalo de confiança estritamente menor que 3 , podendo inferir que os respondentes discordaram das questões relacionadas a esse indicador. Ou seja, os respondentes não pensaram em sair da organização devido à dificuldade de conciliar questões pessoais e profissionais, nem entendem que isso seja uma das principais dificuldades que enfrentam. Novamente, quando se considera as respostas sem diferenciação por sexo, não é de se estranhar que a percepção geral é de que o equilíbrio trabalho-família é fácil de ser alcançado, já que esta é a percepção majoritária dos homens (Tanure et al., 2014; Valadares, 2016).

A questão 17 (me sinto confortável em recusar uma demanda de trabalho), apresentou uma média significativamente maior que as demais questões do indicador Trabalho e Família (embora ainda abaixo de 3). No ambiente de negócios em geral, tanto para homens quanto para mulheres no conjunto, não é confortável recusar demandas de trabalho.

\subsection{COMPARAÇÃO COM AS VARIÁVEIS DE CARACTERIZAÇÃO}

\subsubsection{Carreira}

Nesta seção, foi feita uma comparação de cada indicador com as variáveis de caracterização dos respondentes com o intuito de encontrar relações categóricas.

Tabela 4

Indicador Carreira

\begin{tabular}{ll|c|c|c|c|c|c|c}
\hline & \multicolumn{1}{c}{ Variável } & N & Média & E.P. & 1o Q. & 20 Q. & 30 Q. & Valor-p \\
\hline Sexo & Feminino & 147 & 3,14 & 0,07 & 2,55 & 3,01 & 3,79 & $<0,001^{1}$ \\
& Masculino & 86 & 3,75 & 0,08 & 3,25 & 3,84 & 4,34 & \\
Estado & Com acompanhante & 159 & 3,46 & 0,07 & 2,84 & 3,55 & 4,27 & $0,202^{1}$ \\
Civil & Sem acompanhante & 92 & 3,32 & 0,1 & 2,65 & 3,25 & 4,1 & \\
Cargo & Analista/Supervisor & 112 & 3,24 & 0,09 & 2,62 & 3,25 & 3,98 & $0,045^{2}$ \\
& Assistente/Técnico & 57 & 3,58 & 0,11 & 2,86 & 3,68 & 4,29 & \\
& Coordenador/Especialista & 34 & 3,33 & 0,16 & 2,54 & 3,68 & 3,95 & \\
& Diretor/Gerente & 12 & 3,94 & 0,22 & 3,26 & 4,26 & 4,54 & \\
& Operador/Auxiliar & 44 & 3,53 & 0,14 & 3 & 3,43 & 4,3 & \\
Local de & Estrutura Operacional 4/ GO & 36 & 3,56 & 0,15 & 2,99 & 3,58 & 4,32 & $0,002^{2}$ \\
trabalho & Estrutura Corporativa/ MG & 94 & 3,2 & 0,1 & 2,53 & 3,25 & 4,03 & \\
& Estrutura Operacional 1/ MG & 74 & 3,31 & 0,1 & 2,58 & 3,29 & 3,93 & \\
& Estrutura Operacional 3/ RJ & 31 & 3,9 & 0,13 & 3,27 & 3,96 & 4,37 & \\
& Outros & 27 & 3,7 & 0,15 & 3,04 & 3,68 & 4,36 & \\
\hline
\end{tabular}

${ }^{1}$ Teste de Mann- Whitney; ${ }^{2}$ Teste de Kruskal-Wallis; ${ }^{3}$ Teste de Nemenyi. 
Analisando os dados da Tabela 4, observa-se que houve diferença significativa (valor$p<0,001$ ) de percepção entre o sexo feminino e masculino quanto ao indicador Carreira, sendo que os indivíduos do sexo masculino apresentaram a maior média do indicador, ou seja, maior tendência a concordância. Ao contrário do item anterior, aqui se considera as respostas com diferenciação por sexo. Claramente os homens, que estão na zona de conforto do dominador, percebem menos as barreiras à carreira das mulheres do que elas próprias, o que não surpreende. Os dados revelam que os homens não percebem que as oportunidades de crescimento na organização não são igualitárias para ambos os sexos. Tal achado indica um não reconhecimento das barreiras enfrentadas pelas mulheres no mundo do trabalho, como salienta a literatrura (Abramo, 2007; Carvalho Neto et al, 2010; Mota-Santos et al., 2019; Hirata \& Kergoat, 2007; Nascimento, 2014; Reis et. al., 2018; Rocha-Coutinho \& Coutinho, 2011; Silva et al., 2016; Vieira \& Amaral, 2013).

Quanto aos cargos ocupados pelos respondentes, também foi identificada uma diferença significativa (valor-p $=0,045$ ) em relação ao indicador Carreira. Ou seja, os indivíduos que ocupavam o cargo de diretor/gerente apresentaram a maior média do indicador, o que evidencia a tendência desse grupo de reforçar o discurso organizacional até mesmo em função da posição que ocupam. Por outro lado, não houve diferença significativa de percepção entre o estado civil e o indicador Carreira (Valor-p =0,202).

Entre os locais de trabalho também foi identificada uma diferença significativa (valor$p=0,002$ ) de percepção quanto ao indicador Carreira, sendo que os indivíduos que trabalhavam na Estrutura Operacional 3/RJ apresentaram a maior média do indicador. Os profissionais desta Estrutura Operacional 3/RJ apresentaram uma percepção mais positiva em relação à capacidade da mulher de exercer qualquer função, aproveitar oportunidades de carreira e alcançar equidade salarial. Novamente, o número de homens trabalhando neste local influenciou positivamente nesta falta de percepção sobre as barreiras enfrentadas pelas mulheres: somente $26 \%$ do total de respondentes deste local de trabalho é do sexo feminino. Há, portanto, um predomínio da visão masculina neste local. Esta falta de empatia do homem em relação às dificuldades encontradas pelas mulheres é ressaltada na literatura (Silva et al., 2016; Antunes et al., 2018; Mota-Santos et al., 2019).

A Tabela 5 contempla a correlação entre as variáveis numéricas e o indicador Carreira.

Tabela 5

Correlação entre as variáveis numéricas e o indicador Carreira

\begin{tabular}{lcc}
\multicolumn{1}{c|}{ Variáveis } & $\mathbf{r}^{\mathbf{1}}$ & Valor-p \\
\hline Idade & $-0,03$ & 0,657 \\
Tempo de trabalho & $-0,15$ & 0,015 \\
Escolaridade & $-0,21$ & 0,001 \\
Número de filhos & 0,07 & 0,262 \\
\hline${ }^{1}$ rho de Spearman. & &
\end{tabular}

Observa-se uma correlação significativa (valor- $p=0,015)$ e negativa $(r=-0,15)$ entre o tempo de trabalho e o indicador Carreira. Os empregados com mais tempo de empresa apresentaram menor nível de concordância em relação a questões que tratam da capacidade da mulher de exercer qualquer função na organização, da oportunidade de ascensão e desenvolvimento de carreira ser igualitária entre homens e mulheres e da equidade salarial. Isso reforça a percepção das barreiras à carreira feminina nas organizações salientada pela 
literatura, já que os trabalhadores com mais tempo de serviço têm um olhar mais voltado à história das políticas e práticas de RH da empresa, e percebem que há barreiras.

A mesma relação foi identificada entre a escolaridade e o indicador Carreira, que também apresentou correlação significativa (valor- $p=0,001)$ e negativa $(r=-0,21)$. Ou seja, quanto maior o grau de escolaridade, menor tende a ser o escore do indicador Carreira e viceversa. Quanto maior o grau de escolaridade, portanto, maior a percepção de que existem barreiras à carreira da mulher, como aponta a literatura (Antunes et al., 2018; Bruschini, 1994; Carvalho Neto et al., 2010; Mota-Santos et al., 2019; Rocha-Coutinho \& Coutinho, 2011; Silva et al., 2016; Teixeira, 2009). Os trabalhadores mais qualificados em uma mineradora estão alocados em sua maioria em áreas táticas e estratégicas, sempre mais próximas à cúpula gerencial da organização, portanto mais influenciados pelo discurso organizacional, neste caso de impulso a um programa de gestão da diversidade e inclusão.

Por fim, não houve correlação significativa entre as variáveis idade e número de filhos em relação ao indicador Carreira (Valor- $p>0,05$ ).

\subsubsection{Preconceito e discriminação}

A Tabela 6 apresenta uma comparação entre as variáveis de caracterização dos respondentes e o indicador Preconceito e Discriminação. Analisando os dados, observa-se uma diferença significativa de percepção (valor- $p<0,001$ ) entre o sexo feminino e masculino quanto ao indicador Preconceito e Discriminação, sendo que as mulheres apresentaram a maior média do indicador.

Tabela 6

Indicador Preconceito e Discriminação.

\begin{tabular}{ll|c|c|c|c|c|c|c}
\hline & \multicolumn{1}{c}{ Variável } & N & Média & E.P. & 10 Q. & 20 Q. & 3o Q. & Valor-p \\
\hline Sexo & Feminino & 147 & 3,17 & 0,1 & 2,34 & 3,24 & 4,19 & $<0,001^{1}$ \\
& Masculino & 86 & 2,2 & 0,1 & 1,31 & 2,1 & 3,02 & \\
Estado & Com acompanhante & 159 & 2,64 & 0,1 & 1,48 & 2,63 & 3,66 & $0,071^{1}$ \\
Civil & Sem acompanhante & 92 & 2,94 & 0,13 & 1,68 & 3,01 & 3,95 & \\
Cargo & Analista/Supervisor & 112 & 3,06 & 0,12 & 1,83 & 3,14 & 4,15 & $<0,001^{2}$ \\
& Assistente/Técnico & 57 & 2,52 & 0,14 & 1,55 & 2,67 & 3,44 & \\
& Coordenador/Especialista & 34 & 2,91 & 0,21 & 1,67 & 3,03 & 3,78 & \\
& Diretor/Gerente & 12 & 1,91 & 0,22 & 1,22 & 1,88 & 2,49 & \\
& Operador/Auxiliar & 44 & 2,25 & 0,16 & 1,26 & 2,43 & 2,96 & \\
Local de & Estrutura Operacional 4/ GO & 36 & 2,51 & 0,15 & 1,74 & 2,57 & 3,05 & $0,015^{2}$ \\
& Estrutura Corporativa/ MG & 94 & 3,02 & 0,14 & 1,89 & 3,13 & 4,21 & \\
& Estrutura Operacional 1/ MG & 74 & 2,8 & 0,14 & 1,67 & 2,94 & 3,86 & \\
& Estrutura Operacional 3/ RJ & 31 & 2,22 & 0,22 & 1 & 1,76 & 3,28 & \\
& Outros & 27 & 2,47 & 0,22 & 1,37 & 2,88 & 3,32 &
\end{tabular}

${ }^{1}$ Teste de Mann- Whitney; ${ }^{2}$ Teste de Kruskal-Wallis; ${ }^{3}$ Teste de Nemenyi.

Esse resultado evidencia uma percepção mais aguçada das mulheres quanto à ocorrência de situações que envolvem bullying, assédio moral e sexual na organização, entre outros. Resultado esperado, como aponta a literatura, já que são as mulheres as vítimas destes abusos (Mota-Santos, 2012; Valadares, 2016).

Observa-se uma diferença significativa de percepção (valor-p $<0,001$ ) entre o sexo feminino e masculino quanto ao indicador Preconceito e Discriminação, sendo que as 
mulheres apresentaram a maior média do indicador. Esse resultado evidencia uma percepção mais aguçada das mulheres quanto à ocorrência de situações que envolvem bullying, assédio moral e sexual na organização, entre outros. Resultado esperado, como aponta a literatura, já que são as mulheres as vítimas destes abusos (Mota-Santos, 2012; Valadares, 2016).

Quanto aos cargos ocupados pelos respondentes, também foi observada uma diferença significativa (valor- $p<0,001$ ) de percepção em relação ao indicador Preconceito e Discriminação. Os respondentes que ocupavam o cargo de analista/supervisor apresentaram a maior média do indicador, isto é, maior tendência de concordância.

Além disso, por comparações múltiplas, os analistas/supervisores apresentaram uma média significativamente maior em relação aos indivíduos que ocupavam o cargo de operador/auxiliar (Valor- $\left.\mathrm{p}^{3}=0,009\right)$. Nessa linha, pode-se concluir que a percepção de situações de preconceito e discriminação foi mais evidente para os cargos de analista/supervisor do que para os profissionais do nível operacional. Esse dado reflete o fato de que a maioria dos profissionais que ocupavam o cargo de analista/supervisor está concentrada na Estrutura Corporativa de MG, onde o discurso organizacional de inclusão está mais presente do que na operação. Aqui vale a mesma análise desenvolvida acima, sobre a maior proximidade destes trabalhadores com a cúpula da organização e/ou com seu discurso de inclusão, antidiscriminação.

Estudos que tratam da mulher no ambiente da mineração indicam que situações de preconceito e discriminação são mais evidentes no nível da operação, por ser este o local onde a força de trabalho é majoritariamente masculina (Abramo, 2007; Carrilho, 2016; Quirino, 2011), o que corrobora os achados identificados no presente estudo.

Por fim, entre o estado civil e o indicador Preconceito e Discriminação não foi identificada diferença significativa de percepção (Valor-p =0,071).

A Tabela 7 contempla a correlação entre as variáveis e o indicador Preconceito.

Tabela 7

Correlação entre as variáveis numéricas e o indicador Preconceito e Discriminação

\begin{tabular}{lcc}
\multicolumn{1}{c|}{ Variáveis } & $\mathbf{r}^{\mathbf{1}}$ & Valor-p \\
\hline Idade & $-0,15$ & 0,02 \\
Tempo de trabalho & 0,13 & 0,042 \\
Escolaridade & 0,26 & $<0,001$ \\
Número de filhos & $-0,2$ & 0,001 \\
\hline
\end{tabular}

${ }^{1}$ rho de Spearman.

Os dados apresentados evidenciam uma correlação significativa (valor- $p=0,020$ ) e negativa $(r=-0,15)$ entre a idade e o indicador Preconceito e Discriminação, indicando que, quanto maior a idade do respondente, menor tende a ser o escore do indicador avaliado. Para o jovem, a pouca experiência de vida certamente contribui para uma menor percepção do preconceito que leva à discriminação, muitas vezes manifestado de forma sutil.

Entre o tempo de trabalho e o indicador Preconceito e Discriminação foi identificada uma correlação significativa (valor- $p=0,042$ ) e positiva $(r=0,13)$. Ou seja, quanto maior o tempo de trabalho, maior tende a ser o escore do indicador Preconceito e Discriminação. Isso indica que os respondentes mais velhos, por terem convivido mais tempo com a realidade organizacional, possuem uma percepção mais aguçada da ocorrência de situações de preconceito e discriminação na organização investigada, como salienta a literatura. 
Para a escolaridade, também foi identificada uma correlação significativa (valor-p < $0,001)$ e positiva $(r=0,26)$. Ou seja, quanto maior o grau de escolaridade do funcionário, maior tende a ser o escore do indicador Preconceito e Discriminação e vice-versa. Esse achado indica que os respondentes com maior nível de escolaridade possuem uma percepção mais aguçada da ocorrência de situações de preconceito e discriminação na organização investigada, situação já discutida acima.

\subsubsection{Trabalho e família}

A Tabela 8 contempla uma comparação entre as variáveis de caracterização dos respondentes e o indicador Trabalho e Família.

Tabela 8

Indicador Trabalho e Família

\begin{tabular}{ll|c|c|c|c|c|c|c}
\hline & \multicolumn{1}{c}{ Variável } & N & Média & E.P. & 10 Q. & 20 Q. & 3o Q. & Valor-p \\
\hline Sexo & Feminino & 147 & 2,35 & 0,11 & 1 & 2 & 3,5 & 0,612 \\
& Masculino & 86 & 2,38 & 0,13 & 1 & 2,5 & 3 & \\
Estado & Com acompanhante & 159 & 2,58 & 0,1 & 1,25 & 2,5 & 3,5 & 0,001 \\
Civil & Sem acompanhante & 92 & 2,03 & 0,12 & 1 & 1,75 & 3 & \\
Cargo & Analista/Supervisor & 112 & 2,52 & 0,12 & 1,5 & 2,5 & 3,5 & 0,013 \\
& Assistente/Técnico & 57 & 2,18 & 0,18 & 1 & 2 & 3 & \\
& Coordenador/Especialista & 34 & 2,78 & 0,23 & 1,5 & 3 & 4 & \\
& Diretor/Gerente & 12 & 2,79 & 0,35 & 2 & 2,5 & 3,75 \\
Local de & Eperador/Auxiliar & 44 & 2,05 & 0,15 & 1 & 2 & 2,75 \\
trabalho & Estrutura Operacional 4/ GO & 36 & 2,35 & 0,24 & 1 & 2 & 3,75 & 0,003 \\
& Estrutura Corporativa/ MG & 94 & 2,57 & 0,13 & 1,5 & 2,5 & 3,5 & \\
& Estrutura Operacional 1/ MG & 74 & 2,64 & 0,15 & 1,5 & 2,5 & 3,5 \\
& Estrutura Operacional 3/ RJ & 31 & 1,81 & 0,19 & 1 & 1,5 & 2,5 \\
& Outros & 27 & 1,98 & 0,2 & 1 & 2 & 2,75
\end{tabular}

${ }^{1}$ Teste de Mann- Whitney; ${ }^{2}$ Teste de Kruskal-Wallis; ${ }^{3}$ Teste de Nemenyi

Quanto ao sexo do respondente, os dados empíricos apontam que não houve diferença significativa (Valor- $p=0,612$ ) de percepção em relação ao indicador Trabalho e Família, achado que contrasta a literatura que aponta predominantemente que as profissionais do sexo feminino têm mais dificuldade de equilibrar o trabalho com questões pessoas/familiares (Abramo, 2007; Carvalho Neto et al, 2010; Mota-Santos et al., 2019; Hirata \& Kergoat, 2007; Nascimento, 2014; Reis et. al., 2018; Rocha-Coutinho \& Coutinho, 2011; Silva et al., 2016; Vieira \& Amaral, 2013). Uma das limitações desta pesquisa quantitativa é a impossibilidade de verificar por que as mulheres, nesta questão específica (e somente nesta), não perceberam a dificuldade. De toda forma, em todas as outras questões que impactam a percepção de maiores dificuldades para as mulheres, os achados deste estudo corroboraram a literatura.

Seguindo, contata-se que houve diferença significativa (valor-p $=0,001)$ de percepção entre pessoas com e sem acompanhantes (parceiros amorosos com os quais têm união duradoura) quanto ao indicador Trabalho e Família, sendo que os indivíduos com acompanhante apresentaram a maior média do indicador (embora ainda abaixo de 3). Tal achado indica que os respondentes com acompanhante se sentem mais confortáveis em recusar uma reunião por questões pessoais e possuem uma tendência maior de sair da empresa em função de incompatibilidade de assuntos pessoais e profissionais em relação aos respondentes sem acompanhantes. Este achado corrobora a literatura. 
Quanto ao cargo do respondente, contata-se que houve diferença significativa (valor$p=0,013)$ de percepção em relação ao indicador Trabalho e Família, sendo que os diretores/gerentes apresentaram a maior média do indicador. Os dados apontam que 58\% dos diretores/gerentes não se sentem confortáveis em recusar uma demanda de trabalho por questões pessoais e possuem dificuldades em conciliar trabalho e vida pessoal. Isso se deve ao fato de que, nestes cargos, as solicitações para atender a variadas demandas são maiores e mais comuns do que em cargos operacionais, ainda mais em uma empresa mineradora, onde as tarefas de nível operacional são bastante previsíveis e rotineiras.

Ressalta-se, ainda, que as duas mulheres que são gerentes/diretoras da organização não estão incluídas nos percentuais citados anteriormente, ou seja, elas não concordaram sobre já ter pensado em sair da empresa por dificuldade de conciliar questões pessoais e profissionais, assim como não percebem essa como uma das principais dificuldades que enfrentam na atualidade. Tal achado pode ser explicado pelo fato de que, quando algumas mulheres alcançam cargos gerenciais e consequentemente melhoram os seus rendimentos financeiros, elas acabam terceirizando parte das funções do lar, como apontado pela literatura (Carvalho Neto et al., 2010; Mota-Santos, 2012).

A Tabela 9 contempla a correlação entre as variáveis e o indicador Trabalho e Família.

Tabela 9

Correlação entre as variáveis numéricas e o indicador Trabalho e Família

\begin{tabular}{l|c|c}
\multicolumn{1}{c|}{ Variáveis } & $\mathbf{r}^{\mathbf{1}}$ & Valor-p \\
\hline Idade & 0,11 & 0,083 \\
Tempo de trabalho & 0,19 & 0,002 \\
Escolaridade & 0,17 & 0,005 \\
Número de filhos & 0,14 & 0,026 \\
\hline${ }^{1}$ rho de Spearman. & & \\
\hline
\end{tabular}

Observa-se uma correlação significativa (valor- $p=0,002)$ e positiva $(r=0,19)$ entre o tempo de trabalho e o indicador Trabalho e Família. Sendo assim, quanto maior o tempo de casa do funcionário, maior tende a ser o escore do indicador Trabalho e Família. Esse resultado evidencia que um funcionário com mais tempo de trabalho na empresa se sente mais confortável em recusar uma demanda de trabalho em função de uma questão pessoal. Em contrapartida, um funcionário com mais tempo de empresa já pode ter pensado em sair da organização devido aos desafios de conciliar vida pessoal e profissional.

Entre o item escolaridade e o indicador Trabalho e Família também houve correlação significativa (valor- $p=0,005)$ e positiva $(r=0,17)$. Assim, quanto maior o grau de escolaridade do funcionário, maior tende a ser o escore do indicador Trabalho e Família e vice-versa. As solicitações para atender a demandas não previstas são maiores e mais comuns para o pessoal mais qualificado, que trabalha em posições onde há uma maior complexidade, imprevisibilidade e variabilidade de tarefas do que em cargos operacionais, ainda mais em uma empresa mineradora, onde as tarefas de nível operacional são bastante previsíveis e rotineiras.

Quanto ao número de filhos e o indicador Trabalho e Família, também houve correlação significativa (valor- $p=0,026)$ e positiva $(r=0,14)$. Portanto, quanto maior o número de filhos, maior o nível de concordância do respondente em relação às questões apresentadas, o que corrobora a literatura, e é esperado. 


\section{CONSIDERAÇÕES FINAIS}

Embora a percepção sobre barreiras em relação à carreira da mulher fosse muito pequena, e esta é uma dimensão que a literatura considera das mais difíceis de ser percebida pelas próprias mulheres, os dados referentes aos indicadores de Preconceito e Discriminação e Trabalho e Família corroboraram amplamente a literatura.

Ainda que não se tenha percebido tanto as barreiras quanto à carreira, os empregados com mais tempo de empresa enxergaram mais estas barreiras à carreira feminina, o que nos permite inferir que há sim dificuldades, já que estes trabalhadores são exatamente aqueles que possuem um conhecimento mais amplo das políticas e práticas de RH da organização e das situações que as mulheres vivenciam no ambiente de trabalho ao longo do tempo. Também vão ao encontro da literatura os dados que revelaram que os homens, além de não perceberem o preconceito e a discriminação, e mostrarem pouca empatia em relação à dupla jornada de trabalho das mulheres, não percebem diferenças salariais entre homens e mulheres nem que as oportunidades de desenvolvimento na organização são igualitárias para ambos os sexos.

Os homens que trabalham na mineração, um setor econômico que tem um histórico atroz de dominação masculina, ainda mais que em outros setores da economia, como mostra a literatura específica desta atividade econômica, sequer se dignaram a responder ao questionário da pesquisa em número proporcional ao respondido pelas mulheres, mesmo com a presidência da mineradora e diretores patrocinando a iniciativa, que está dentro de um programa mundial de inclusão deslanchado pela holding mundial na América Latina, África e América do Norte. Esta recusa dá uma dimensão do tamanho do desafio que as mulheres enfrentam na mineração.

Dentro deste quadro atroz de dominação masculina na mineração, não é de se estranhar a diferença significativa de percepção entre o sexo feminino e masculino, quanto ao indicador Preconceito e Discriminação. As mulheres, como as maiores vítimas de preconceito e discriminação por parte dos homens, e mesmo por parte daquelas mulheres que são defensoras e propagadoras dos valores machistas do patriarcado, claramente sentem de forma diferente dos homens a ocorrência destas situações na organização investigada.

A percepção de situações de preconceito foi mais evidente para os cargos de supervisor do que para os profissionais do nível operacional, já que os gestores são via de regra muito mais suscetíveis ao discurso institucional da organização de inclusão e de combate ao preconceito e à discriminação. Na área da administração, há poucas pesquisas sobre o nível operacional, e esta pode ser uma interessante agenda de pesquisa. Afinal, na área operacional encontra-se a esmagadora maioria dos trabalhadores, tão responsáveis quanto os gestores pelos atos de discriminação a partir de preconceitos arraigados e de difícil combate. Uma maior atenção à área operacional é absolutamente necessária para o sucesso de qualquer política de inclusão e diversidade.

Quanto às contribuições do estudo, a pesquisa confirma algumas barreiras vivenciadas pelas mulheres no quesito ascensão e desenvolvimento de carreira e corrobora a existência de situações de preconceito e discriminação em contextos marcados pela hegemonia do masculino, como é o caso da mineração.

Por fim, outra contribuição está em investigar um tema pouco debatido no Brasil, ou seja, a condição de trabalho da mulher na mineração foi abordada em apenas um estudo nacional (Macedo et al., 2012). Ademais, ao trazer à tona esse debate, o presente estudo reforça a importância de se pensar na elaboração de políticas e práticas de recursos humanos 
focadas nas necessidades da mulher para que elas possam obter iguais condições de trabalho, de salário e de ascensão nas organizações.

Este estudo apresenta a limitação de não ter permitido um aprofundamento nas questões levantadas, por ter se constituído em pesquisa quantitativa. Como outras limitações do estudo, destaca-se a ênfase da pesquisa em três dimensões da condição de trabalho da mulher na mineração (carreira; preconceito; trabalho/família), desconsiderando outras categorias relevantes, como as políticas e práticas de recursos humanos voltadas para a mulher. Outra limitação diz respeito ao uso de instrumento único para a coleta de dados (o questionário), impossibilitando a triangulação dos achados.

Assim, a partir dos resultados aqui apresentados, abre-se uma agenda de pesquisa qualitativa neste setor ainda pouco pesquisado, para buscar compreender por que a maioria das mulheres neste estudo disse que não há dificuldades em equilibrar trabalho e obrigações familiares, o que contraria a literatura.

Ademais, complementando as proposições para uma agenda de pesquisa, este estudo propõe um questionário com questões relacionadas à três dimensões da literatura sobre o ambiente de trabalho da mulher, que podem ser aplicados em outros contextos, bem como refinados para estudos futuros.

\section{REFERÊNCIAS}

Abramo, L. W. (2007). A Inserção da mulher no mercado de trabalho: uma força de trabalho secundária. [Tese de Doutorado, Universidade de São Paulo]. Repositório da Universidade de São Paulo. https://www.teses.usp.br/teses/disponiveis/8/8132/tde23102007-141151/pt-br.php.

Andrade, T. (2016). Mulheres no mercado de trabalho: onde nasce a desigualdade. Brasília: Câmara dos Deputados, Consultoria Legislativa. (Estudo técnico). https://bd.camara.leg.br/bd/handle/bdcamara/29160?_ga= 2.52779112.1318554745.1613295434-275702430.1613295434.

Antunes, C. V., Carvalho-Neto, A., Lima-Souza, E. C. P., \& Santos, C. M. M. (2018). O que eles pensam sobre elas? Representações sociais da mulher executiva. Revista Alcance, 25(3), 349-365. https://doi.org/10.14210/alcance.v25n3(Set/Dez).p349-365.

Brasil. (2019). Ministério do Trabalho e Emprego. Relatório Anual de Informações Sociais 2019. Brasília: MTE. http://www.mte.org.br/htm.

Bruschini, C. (1994). O trabalho da mulher brasileira nas décadas recentes. Estudos Feministas, (n. e.), 179-199. https://doi.org/10.1590/\%25x.

Bruschini, C., \& Lombardi, M. R. (2016). O trabalho da mulher brasileira nos primeiros anos da década de noventa. In Anais do 10 Encontro Nacional de Estudos Populacionais. (pp. 483-516). Belo Horizonte: ENEP.

Buss, D., Rutherford, B., Stewart, J., Côté, G. E., Sebina-Zziwa, A., Kibombo, R., Lebert, J. (2019). Gender and artisanal and small-scale mining: Implications foralization. The Extractive Industries and Society, 6(4), 1101-1112. 
Cappelle, M. C. A., Melo, M. C. O. L., \& Souza, N. L. (2013). Mulher, trabalho e administração. Revista Interdisciplinar de Gestão Social, 2(2), 161-191. http://dx.doi.org/10.9771/23172428rigs.v2i2.9875.

Carrilho, A. (2016). Mulheres Invisíveis, mas necessárias: a negação da feminização no trabalho da mineração. [Tese de Doutorado, Universidade de Brasília]. Repositório da Universidade de Brasília. https://repositorio.unb.br/handle/10482/22237.

Carvalho Neto, A. M., Tanure, B., \& Andrade, J. (2010). Executivas: carreira, maternidade, amores e preconceitos. RAE-eletrônica, 9(1), 1-23.

Castilhos, Z. C., \& Castro, N. F. (2006) Mulheres na mineração: restitutio quae sera tamem. In Z. N., Castilhos, M. H., Machado, R. L., \& N. F. Castro (Orgs.). Gênero e trabalho infantil na pequena mineração: Brasil, Peru, Argentina Bolívia. (p. 41-64). Rio de Janeiro: CETEM/MCT.

Costa, F. M. S. (2020). A apropriação do trabalho reprodutivo pelo trabalho em domicílio. [Dissertação de Mestrado, Puc Minas]. Repositório da PUC Minas. http://www.biblioteca.pucminas.br/teses/Direito_FlaviaMariaDaSilvaCosta_8263.pdf.

Daniel, C. (2011). O trabalho e a questão de gênero: a participação de mulheres na dinâmica do trabalho. O Social em Questão, 14(25/26), 323-344.

http://osocialemquestao.ser.puc-

rio.br/cgi/cgilua.exe/sys/start.htm?infoid=36\&sid=14.

Efron, B., \& Tibshirani, R. J. (1993). An introduction to the bootstrap. New York: Chapman Hall.

Fuentealba, P. S. G., \& Gutiérrez, N. A. (2018) Equidad de género en la gran minería del cobre de Chile. Experiencias de inserción laboral feminina en espacios masculinizados. Revista Temas Sociológicos, (22), 49-85. https://doi.org/10.29344/07196458.22.1678.

Galeazzi, I. M. S., Garcia, L., Driemeier, M. M., Toni, M. D., Kreling, N. H., \& Follador, P. (2011). Mulheres trabalhadoras: 10 anos no mercado de trabalho atenuam desigualdades. Mulher e Trabalho, 3, 9-36.

http://revistas.planejamento.rs.gov.br/index.php/mulheretrabalho/article/view/2690/ 3012.

Gibb, S. J., Fergusson, D. M., Horwood, L. J., \& Boden, J. M. (2014). The effects of parenthood on workforce participation and income for men and women. Journal of Family and Economic Issues, 35(1), 14-26. https://doi.org/10.1007/s10834-013-9353-4.

Gil, A. C. (2002). Como elaborar projetos de pesquisa. São Paulo: Atlas.

Guiraldelli, R. (2012). Adeus à divisão sexual do trabalho? Desigualdade de gênero na cadeia produtiva da confecção. Sociedade e Estado, 27(3). https://doi.org/10.1590/S010269922012000300014. 
Henderson, P. A., Ferreira, M. A. A., \& Dutra, J. S. (2016). As barreiras para ascensão da mulher a posições hierárquicas: um estudo sob a ótica da gestão da diversidade no Brasil. Revista de Administração da UFSM, 9(3), 489-505. https://doi.org/10.5902/198346598208.

Hirata, H., \& Kergoat, D. (2007). Novas configurações da divisão sexual do trabalho. Cadernos de Pesquisa, 37(132), 595-609. http://dx.doi.org/10.1590/S0100-15742007000300005.

Hollander, M., \& Wolfe, D. A. (1999). Nonparametric statistical methods. (2a ed.) NY: John Wiley.

Instituto Brasileiro de Geografia e Estatística (2021). Estatísticas de gênero. Rio de Janeiro: IBGE. https://biblioteca.ibge.gov.br/visualizacao/livros/liv101784_informativo.pdf.

Macedo, F. M. F., Boava, D. L. T., Cappelle, M. C. A., \& Oliveira, M. L. S. (2012). Relações de gênero e subjetividade na mineração. Revista de Administração, 16(2), 217-236. https://doi.org/10.1590/S1415-65552012000200004.

Mota-Santos, C. M. (2012). As mulheres brasileiras: do espaço privado da casa para as posições executivas nas organizações brasileiras. [Tese de Doutorado, PUC Minas]. Repositório da PUC Minas. http://www.biblioteca.pucminas.br/teses/Administracao_SantosCMM_1.pdf.

Mota-Santos, C. M., \& Carvalho-Neto, A. M. (2017). O papel da família na trajetória de mulheres executivas e empreendedoras. Revista Alcance, 24(1), 36-49. https://doi.org/10.14210/alcance.v24n1.p036-049.

Mota-Santos, C., Carvalho Neto, A., Oliveira, P., \& Andrade, J. (2019). Reforçando a contribuição social de gênero: a servidora pública qualificada versus a executiva. Revista de Administração Pública, 53(1), 101-123. http://dx.doi.org/10.1590/0034761220170156.

Nascimento. S. D. (2014). Precarização do trabalho feminino: a realidade das mulheres no mundo do Trabalho. Revista Temporalis, 14(28), 39-56. https://doi.org/10.22422/2238-1856.2014v14n28p39-56.

Norberg, C., \& Fältholm, Y. (2018). "Learn to blend in!": a corpus-based analysis of the representation of women in mining. Equality, Diversity and Inclusion, 37(7), 98-712. https://doi.org/10.1108/EDI-12-2017-0270.

Oliveira, I. G. S., Cardoso, S. P., Dias, R. S., \& Borges Júnior, R. (2018). Influence of female boardroom presence on firm value: an analysis on companies listed on B3. Revista de Negócios, 23(3), 49-57. http://dx.doi.org/10.7867/1980-4431.2018v23n3p49-57.

Pimpa, N. (2019). How mining companies promote gender equality through sustainable development? Cogent Business \& Management, 6(1), 1647590. https://doi.org/10.1080/23311975.2019.1647590. 
Mulheres na mineração: carreira, equilíbrio trabalho-família e discriminação

Pinto, C. R. J. (2010). Feminismo, história e poder. Revista Sociologia Política, 18(36), 15-23.

Quirino, R. (2011). Mineração também é lugar de mulher! Desvendando a (nova?!) face da divisão sexual do trabalho na Mineração de Ferro. (Tese de Doutorado, Universidade Federal de Minas Gerais]. Repositório da UFMG.

https://repositorio.ufmg.br/handle/1843/BUOS-8NTGLQ.

Reis, T. A., Dias, A. S., Oliveira, E. O., Costa, J. A., Cremonezi, G. O., \& Spers, V. R. E. (2018). Desafios e Conflitos da mulher na busca da ascensão na carreira profissional. Revista de Carreiras e Pessoas, 8(3), 398-412.

Reis, S. J., Mota-Santos, C. M., \& Teixeira, M. B. M (2020). “Joguei a toalha!": a realidade de executivas que decidiram retornar ao lar. Uma discussão sobre o fenômeno opt-out. Revista de Ciências da Administração, 22(56), 8-26. https://doi.org/10.20503/recape.v8i3.36820.

Rocha-Coutinho, M. L., \& Coutinho, R. R. (2011) Mulheres brasileiras em posições de liderança. Economia Global e Gestão, 16(1), 61-80.

Santos, M. H., \& Amâncio, L. (2014). Sobre minorias em profissões marcadas pelo género: consequências e reações. Análise Social, (212), 700-726.

Silva, P. M. M., Rocha Neto, M. P., Brito, L. M. P., Barreto, L. K. S., \& Gurgel, F. F. (2016). Equidade de gênero nas organizações: o trabalho e os desafios da mulher na construção civil. Organizações em Contexto, 12(24). https://doi.org/10.15603/19828756/roc.v12n24p283-305.

Susskind, R.; \& Susskind, D. (2017) The future of the professions: How technology will transform the work of human experts. Glasgow: Oxford University Press.

Tanure, B., Carvalho Neto, A., \& Mota-Santos, C. (2014). Pride and prejudice beyond the glass ceiling: Brazilian female executives' psychological type. Revista de Ciências da Administração, 16(39), 210-223. https://doi.org/10.5007/2175-8077.2014v16n39p210.

Teixeira, C. M. (2009). As mulheres no mundo do trabalho: ação das mulheres, no setor fabril, para a ocupação e democratização dos espaços público e privado. Psicologia: Teoria e Pesquisa, 25(2), 237-244. https://doi.org/10.1590/S010237722009000200012.

Valadares, B. H. A. (2016). Igualdade de gênero e autonomia das mulheres: estudo das novas práticas adotadas pelas grandes empresas brasileiras. (Dissertação de Mestrado, PUC Minas]. Repositório da PUC Minas.

http://www.biblioteca.pucminas.br/teses/Direito_ValadaresBHA_1.pdf.

Vieira, A., \& Amaral, G. A. (2013). A arte de ser beija-flor na tripla jornada de trabalho da mulher. Saúde e Sociedade, 22(2), 403-414. https://doi.org/10.1590/S010412902013000200012. 